\title{
Patentable Subject Matter: The View from Europe
}

\author{
Avi Freeman ${ }^{\mathrm{a}}$ \\ (a) Partner in Beck Greener, European and UK Patent and \\ Trademark attorneys and litigators
}

DOI: $\underline{\text { 10.5033/ifosslr.v3i1.58 }}$

"Follow! nay, I'll go with thee, cheek by jowl"1

\begin{abstract}
This article presents a review of the position regarding the availability of patent protection for computer-implemented inventions (software in particular) in Europe. The specifics of the European Patent Office approach to this, i.e. providing a low threshold for exclusion on grounds of non-patentable subject matter, but not allowing non-technical features to contribute to an inventive step, is contrasted with that in the United Kingdom, where the EPO-derived "contribution approach" still holds. Some comparisons are made with the position in the United States, post Bilski.
\end{abstract}

\section{Introduction}

Technology and innovation today look very different from how they looked 30 years ago, never mind centuries ago, when early formal patent systems were being established at the time of Statute of Monopolies $1623 .^{2}$ Stained glass windows and salt might have been cutting edge inventions then, but now exactly what counts as an "invention" is of commercial and legal significance in Europe and elsewhere, with parties on all sides having strong and well-rehearsed views. In the area of computerimplemented or software-related inventions, in particular, this divergence of views is apparent.

On the one hand, some software developers and companies feel that patents are an essential tool to protect investment in research and development and thereby encourage innovation. All aspects of proprietary code are to be guarded to the fullest extent possible. In contrast, other companies or organisations adopt an open source approach and may seek to rely on a collaborative and open approach to promote innovation, relying on copyright protection and avoiding patents, and patent thickets especially, also considering the specific statutory exclusions relating to the availability of patent protection for software. Whenever an issue becomes prominent in this area, all arguments are aired. For example, the amicus curiae briefs ${ }^{3}$ filed at the European Patent Office (EPO) in the lead up

1 Demetrius to Lysander, A Midsummer Night's Dream - Act III. Scene 2. William Shakespeare

2 For a brief history with particular reference to the definition of the word "invention", see the introduction to "The Requirement for an Invention in Patent Law”, Justine Pila, OUP

3 Contrast, for example, the submissions of the Irish Free Software Organisation on the one hand, available at 
to the recent Enlarged Board of Appeal (hereinafter "the Enlarged Board") opinion on this subject demonstrate the firm views held across the spectrum.

Whatever position is taken on this, the law in Europe and the UK relating to the protection of computer-implemented inventions (and software in particular) has developed over the decades since the European Patent Convention has been in force. In this paper, I will discuss the current position before the EPO regarding the exclusion of certain subject matter from patentability on the grounds that it is not an "invention". To do this, I will refer to the position in the UK, as the development of the law before the EPO has gone hand-in-hand, or perhaps cheek-by-jowl, with that in the UK. Points arising out of the Opinion of the Enlarged Board, G3/08 issued on 12th May 2010, will be discussed.

I will also briefly comment on the situation in the US, taking into the account the recent Supreme Court decision of Bilski $v$ Kappos $^{4}$ (hereinafter "Bilski"), and trying to identify useful issues in common with (or different from) the situation in Europe.

I will not comment on the various attempts to obtain a European Community regulation on the protection of computer-implemented inventions. Attempts to achieve this have previously failed and, for now, the European patent community has enough on its plate dealing with the changes and development of EPO law in this area. In addition, I will not comment on the law of other national states. For a review of this, see, for example, the paper "Computer Programs As Excluded Patentable Subject Matter", by Brad Sherman. ${ }^{5}$

\section{Patentable Subject Matter in the UK and Europe: the Law}

\subsection{The United Kingdom Patents Act 1977}

Jumping straight into the modern era in the UK, we have today the Patents Act 1977 (hereinafter "the Act") and various minor modifications to it, but essentially the substantive law of patents and patentability is as laid down in Sections 1 to 3 of the Act. These define the requirements for novelty, inventive step and, separately, before one even considers these factors, that you have an invention. The term "invention" is not defined.

A list of exclusions is then laid out, which defines a number of categories of things, which are said not to constitute inventions for the purposes of the Act. In other words, things, which someone who may well consider himself an inventor has come up with, but are deemed excluded subject matter.

The relevant sections of the Act are as follows:

http://documents.epo.org/projects/babylon/eponet.nsf/0/2345317E7EE223B3C1257774004EFBA9/\$File/g308 amicus curiae brief_IFSO en.pdf (accessed 13.9.11) and those of Silicon Economics, Inc, available at http://documents.epo.org/projects/babylon/eponet.nsf/0/1CA3C0F619E79F93C125777400549249/\$File/g308 amicus curiae brief Silicon_Economics en.pdf (also accessed 13.9.11)

4561 U. S. (2010), [130 S. Ct. 3218 (2010)]

5 Includes a country-by-country summary available from WIPO Standing Committee meeting documents at http://www.wipo.int/edocs/mdocs/scp/en/scp 16/scp 16 ref_scp 15 3-annex2.pdf. See also the article entitled "Developments in German case law regarding "Computer-implemented inventions" and some comparison with EPO practice" by Michele Baccelli, Markus Georg Muller and Thomas B. Koch in CIPA Journal, December 2010, Volume 39, Number 12, pp 719 to 722 . It is explained how German case law in this area shares some fundamental features with that of the EPO, i.e. requiring at least some technical elements in a claim so as to avoid exclusion, although stipulating that nontechnical features cannot contribute to inventive step. 
1.-(1) A patent may be granted only for an invention ${ }^{6}$ in respect of which the following conditions are satisfied, that is to say -

(a) the invention is new;

(b) it involves an inventive step;

(c) it is capable of industrial application;

(d) the grant of a patent for it is not excluded by subsections (2)... below... ${ }^{7}$

Sub-section 2 provides the following:

(2) It is hereby declared that the following (among other things) are not inventions for the purposes of this Act, that is to say, anything which consists of -

(a) a discovery, scientific theory or mathematical method;

(b) a literary, dramatic, musical or artistic work or any other aesthetic creation

whatsoever;

(c) a scheme, rule or method for performing a mental act, playing a game or doing

business, or a program for a computer;

(d) the presentation of information.... ${ }^{8}$

This is mitigated by the limitation that

“...the foregoing provision shall prevent anything from being treated as an invention for the purposes of this Act only to the extent that a patent or application for a patent relates to that thing as such."

Thus, we have a list of exclusions, which are set to cover the items that are deemed not good subject matter for a patentable invention. However, these exclusions will only apply if the application or patent relates to that thing "as such". The meaning and interpretation of these words have contributed to a significant body of case law over the years since the Act has been in force.

The scope of the section is quite varied and its different parts seem unconnected. Various attempts have been made over the years to identify what, if anything, links these seemingly disparate set of things. In CFPH L.L.C.'s application, Mr Peter Prescott QC, sitting as a deputy Judge, considered this point. He said:

"When we come to look at the list of excluded items, ... and if we pay careful attention, we can notice that they are like a miscellaneous rag-bag. Except superficially, they do not constitute what logicians call a genus, or logical class."

6 Note that this section does not include the phrase "in all fields of technology". However, given the requirement of Section 130 (7) that states that this section is framed so as to have the same effect as the corresponding provisions of the EPC, it is understood to be implicit. See, for example, The CIPA Guide to The Patents Act, 6th Edition, pp 10 and 11.

7 UK Patents Act 1977, Section 1(1)

8 UK Patents Act 1977, Section 1(2)

9 UK Patents Act 1977, Section 1(2) 
He goes on to say that they were not all excluded for the same reason. Indeed, he states:

“......they were excluded for policy reasons; but the policy may not be at all the same in each case..."

More recently, in the Aerotel decision ${ }^{11}$ in the Court of Appeal, Lord Justice Jacob commented in discussing the same point that:

“...there is no evident underlying purpose lying behind the provisions as a group - a purpose to guide the construction. The categories are there, but there is nothing to tell you one way or the other whether they should be read widely or narrowly.

One cannot form an overall approach to the categories. They form a disparate group - no common, overarching concept, for example, links rules for playing games with computer programs or either of these with methods for doing business or aesthetic creations.... ${ }^{, 12}$

\subsection{The European Patent Convention}

The Act was introduced to replace the Patents Act 1949 so as to give effect to the European Patent Convention (EPC), under which a similar set of provisions exists. Indeed, the UK Patents Act ${ }^{13}$ indicates that Section 1 (amongst others) is supposed to have the same effect as the corresponding provisions of the EPC.

Article 52 of the EPC provides the following:

“1) European patents shall be granted for any inventions, in all fields of technology ${ }^{14}$, provided that they are new, involve an inventive step and are susceptible of industrial application.

(2) The following in particular shall not be regarded as inventions within the meaning of paragraph 1:

(a) discoveries, scientific theories and mathematical methods;

(b) aesthetic creations;

(c) schemes, rules and methods for performing mental acts, playing games or doing business, and programs for computers;

(d) presentations of information. ${ }^{, 15}$

Sub-section 3 then mitigates this effect, just as the corresponding section of the Act does for the exclusions outlined therein. It provides:

(3) Paragraph 2 shall exclude the patentability of the subject-matter or activities referred to therein only to the extent to which a European patent application or European patent relates to such subject-matter or activities as such. ${ }^{16}$

10 [2005] EWHC 1589 (Pat), paragraph 21

11 [2007] RPC 7

12 [2007] RPC 7, paragraph 9

13 UK Patents Act 1977, Section 130

14 The expression "in all fields of technology" was introduced to EPC2000 so as to conform to Article 27 TRIPS Agreement

15 EPC2000, Article 52(1) and (2)

16 EPC2000, Article 52(3) 
As can be seen, save for some minor differences, the wording of the Article 52 EPC is the same as that of Section 1(2) of the Act.

\subsection{Evolution in the United Kingdom From Merrill Lynch to Aerotel}

There is also a string of cases before the Court of Appeal and lower courts in the UK that have led us to the position we are now in. Before presenting a very brief review of a selection of these, it is worth summarising the general method that is used by the UK courts in determining whether or not an invention relates to patentable subject matter (computer programs in particular).

The position adopted by the UK courts is based on what may be called the "contribution approach". An assessment is made by the UK courts (or more normally by an examiner at the United Kingdom Intellectual Property Office (UKIPO) acting in accordance with Practice Notices issued to inform users of the UKIPO practice taking into account decisions of the Courts) to determine whether or not an invention makes a "technical contribution". If it does, then it avoids the exclusions. If it does not, then it does not and the application is refused for failing to relate to an invention. As to what exactly is a "technical contribution", more later.

The string of cases is well known and can be found described in great detail in various cases on this subject. One particularly thorough review is the clearly presented annex to the decision in Aerotel. ${ }^{17}$

One of the first cases in the modern era that brought this matter to prominence was the decision of the Court of Appeal in respect of Merrill Lynch's Application (1989). ${ }^{18}$ This decision brought into the UK the "technical contribution approach" law of the EPO from Vicom, ${ }^{19}$ discussed below. The application related to a business method for managing stocks, implemented using a computer program.

In Merrill Lynch's Appn, Fox LJ said:

“...it cannot be permissible to patent an item excluded by s.1(2) under the guise of an article which contains that item -- that is to say, in the case of a computer program, the patenting of a conventional computer containing that program. Something further is necessary. The nature of that addition is, I think, to be found in the Vicom case where it is stated: "Decisive is what technical contribution the invention makes to the known art". There must, I think, be some technical advance on the prior art in the form of a new result (e.g., a substantial increase in processing speed as in Vicom)..."20

This was then qualified with the "rider", that

“... a novel and non-obvious improvement to an excluded category does not count as a technical improvement...”

In other words,

"inventive excluded matter could not count as a technical contribution",21

17 [2007] RPC 7 This case is of course one of the cases that played a part in the referral to the Enlarged Board of the EPO, G3/08 to be discussed below.

18 [1989] RPC 561

19 T0208/84 OJ EPO 1987, 14

20 As Jacob LJ says in Aerotel, “Thus it was that this Court adopted the EPO's "technical contribution approach"”. [2007] RPC 7, paragraph 84

21 [2007] RPC 7, paragraph 83 
So, for there to be a technical contribution as per the law of the UK, there must be some technical contribution that does not fall within excluded subject matter. A contribution, which is merely an advance in one of the areas of excluded subject matter, does not satisfy this test. A claim directed to such an entity will be found bad for lack of technical contribution. This was the UK's way of interpreting what the "as such" statement at the end of Section 1(2) actually means.

Two further Court of Appeal decisions have been handed down in this general subject area. The first, Gale's Appn..$^{22}$, related to a mathematical algorithm recorded on a Read Only Memory (ROM) chip. The Court of Appeal decided that the invention did relate to excluded subject matter and that

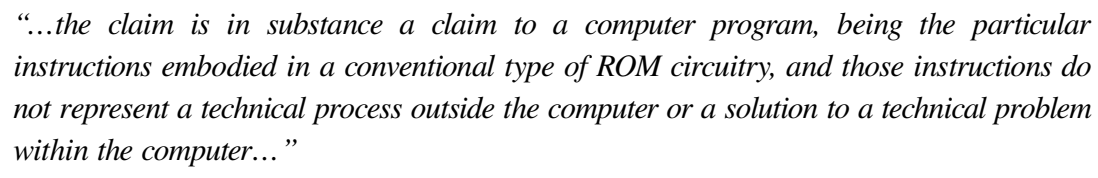

Next, the matter arose again in the case of Fujitsu Limited's application. ${ }^{23}$ The patent application had been refused by the Examiner at the United Kingdom Patent Office (as it was then called) and appealed by the applicant to the High Court and, subsequently, to the Court of Appeal. The invention in question was summed up by Aldous LJ as follows:

\begin{abstract}
"At the heart of the invention is a method for modelling a crystal structure for use in designing inorganic materials in the fields of chemistry and physics. The basic idea utilises a computer programmed so that the operator can select an atom, a lattice vector and a crystal face in each of two crystal structures displayed on the display unit. Upon instruction the computer, using the selected requirements, converts data representing the physical layouts of the two crystal structures into data representing the physical layout of the crystal structure that would be obtained by combining the original two structures in such a way that the two selected structures are superposed. The resulting data is then displayed to give a picture of the combined structure."
\end{abstract}

The judge concluded:

"I believe that the application is for a computer program as such. ... In the present case the combined structure is the result of the directions given by the operator and use of the program. The computer is conventional as is the display unit. The two displays of crystal structures are produced by the operator. The operator then provides the appropriate way of superposition and the program does the rest. The resulting display is the combined structure shown pictorially in a form that would in the past have been produced as a model. The only advance is the computer program which enables the combined structure to be portrayed quicker."

We now have the decision in Aerotel, ${ }^{24}$ referred to above. This restates the law as it had developed to that point and arrives at a four-point test for use by the UKIPO when examining applications in this area. The test was suggested by Comptroller (one of the parties to the case) and accepted by the court as a reasonable way to proceed. The test is as follows:

"(1) properly construe the claim

(2) identify the actual contribution;

22 [1991] RPC 191

23 [1997] RPC 608

24 [2007] RPC 7

International Free and Open Source Software Law Review Vol. 3, Issue 1 
(3) ask whether it falls solely within the excluded subject matter;

(4) check whether the actual or alleged contribution is actually technical in nature". ${ }^{25}$

Subsequent to this, Practice Notices were issued by the UKIPO which confirmed that this is the way such matters will be dealt with.

By and large, this is the situation in the UK today, with one or two modifications or embellishments, but fundamentally, without change in substance. Thus, although there have been cases in the Court of Appeal in this area since Aerotel, the basic four-point test of Aerotel stands. For example, in the recent High Court decision of Gemstar-TV Guide International Inc and others $v$ Virgin Media Limited, ${ }^{26}$ Mann J said,

"The proper approach is plainly the 4 stage test propounded in Aerotel'27

Furthermore, on commenting on the principle of authority he stated,

“...A decision of the Enlarged Board of Appeal is apparently awaited in this area, but I have to apply the law as it has been recently laid down in the Court of Appeal in Symbian Ltd v Comptroller-General of Patents [2009] RPC 1, Aerotel v Telco; Macrossan's Application [2007] RPC 7, together with the benefit of a helpful summary of Lewison J in AT \& T Knowledge Ventures Ltd [2009] EWHC 343.

Aerotel, in so far as it considered the issues before the court, was not in itself controversial. However, in the judgement, a number of inconsistencies and apparently irreconcilable conflicts were identified between the respective positions taken by different EPO Boards of Appeal (hereinafter "the Board(s)").

Indeed, during the time that the UK Court of Appeal had been making the decisions discussed above based largely on the original Vicom "contribution approach", the law in this area before the EPO had developed quite significantly, as I comment in more detail below. While the EPO was able to easily do this, given the flexibility in its systems of decision making, it must be noted that the UK, on the other hand, is not so flexible, which may explain the seeming divergence between current UK jurisprudence and EPO decisions and the Board opinion. In the recent Court of Appeal case of Symbian Limited's application, ${ }^{28}$ this is explained by Lord Neuberger giving the judgement of the court, as follows:

“...the Court of Appeal is bound by one of its previous decisions unless that previous decision is inconsistent with a subsequent decision of the House of Lords (in which case, the previous decision cannot be followed), is inconsistent with an earlier Court of Appeal decision (in which case the court may choose which previous decision to follow), or can be shown to have been arrived at per incuriam (i.e. without reference to a relevant statutory provision or other authority) ...

...Jacob LJ, giving the judgment of the court, held that this court was also free to depart (but not bound to depart) from one of its previous decisions on a point in the field of

25 [2007] RPC 7, paragraph 40

26 [2010] RPC 10, paragraph 34. The decision has recently been upheld by the Court of Appeal (see [2011] EWCA Civ 302) although the issue of excluded subject matter did not arise on appeal since the two patents (out of the three originals) that were the subject of the appeal were found to lack novelty and so excluded subject matter never arose.

27 [2010] RPC 10, paragraph 35

28 [2009] RPC 1 
patent law if satisfied that the Board have formed a settled view on that point, which differs from that arrived at in that previous decision. At [48], Jacob LJ made it clear that the right to depart from a previous decision only arose if the "jurisprudence of the EPO" on the point at issue was "settled", and that, even where that was the case, this court was "not bound to do so": for instance in "the unlikely event" that it thought the jurisprudence was plainly unsatisfactory. ${ }^{, 29}$

In other words, there is an acknowledgement that the decision of the (EPO) Board will have had some influence, especially if it has a "settled" view, but the ultimate guidance to a judge in the UK Patents Court (and indeed to an examiner at the UKIPO), must come from UK authority.

In conclusion, I believe that the law in the UK is thus well-established on this point thanks to a consistent and transparent sequence of cases. The test applied is the four-point test of Aerotel that seeks to establish whether or not a technical contribution is provided. In other words, the approach has been and is to look at the invention, sometimes beyond the language of the claims, and decide if the requisite "technical contribution" is there. ${ }^{30}$

There are advantages and disadvantages to such an approach. Whilst clearly, underlying a claim and its scope is the precise wording that the patentee chooses, in decisions of the High Court on matters relating to infringement or validity, it is the language of the claims that determines the scope of protection (interpreted as necessary). The courts in the UK generally take the view that what matters is the language in the claims by which the patentee has chosen to define his invention, even when with hindsight it appears that an infringer's product has taken the essence of an invention as described in a patent.

However, when it comes to determining whether or not a patent application relates to "an invention", the wording of the claims seems not always to take the highest of positions in factors considered and ruled on by the courts. No doubt there are reasons why the difference in approach is taken. When considering novelty and inventive step, what is being considered is the extent of the exclusion as defined by the claims ${ }^{31}$ that is to be respected by third parties. In contrast, whether or not something is an invention under the Act, Section 1 is perhaps more intrinsic to its nature and, hence, the language chosen for inclusion in the claims by the patentee is not quite of the same importance. "Invention" is, after all, not defined in the Act or the EPC.

It may take a significant number of court decisions for the UK law to change so as to be consistent with the current situation at the EPO, following changes that have taken place concurrently, as commented below.

\subsection{Evolution Before the EPO: from Vicom Onwards}

Turning to the EPO now, as explained above, the 1987 Vicom decision ${ }^{32}$ as mentioned above, is the first significant milestone. There have been many trajectories and changes that have taken place in the law on this area before the EPO since Vicom, but, for the purposes of this paper, I will concentrate on the main issue, which is the creation and adoption of, followed by the departure from, the

29 [2009] RPC 1, paragraph 33

30 See for example, in Fujitsu's Application, where Aldous LJ, on commenting on Fox LJ's judgement in Merril Lynch's Application states "...By that statement Fox LJ was making it clear that it was not sufficient to look at the words of the claimed monopoly. The decision as to what was patentable depended upon substance not form...."

31 UK Patent Act 1977, Section 2 in combination with Section 125(1)

32 T208/84 OJ EPO 1987 
"contribution approach" and the subsequent apparent conflict with the law in the UK. This conflict contributed to the recent referral to the Enlarged Board.

\subsubsection{Vicom - "The Contribution Approach"}

In Vicom, the invention in question related to a method of digital image processing using "operator matrices" for convolving with a data array representing an image.

The Board concluded that:

“...Generally speaking, an invention which would be patentable in accordance with conventional patentability criteria should not be excluded from protection by the mere fact that for its implementation modern technical means in the form of a computer program are used. Decisive is what technical contribution the invention as defined in the claim when considered as a whole makes to the known art...."

The contribution approach was thus established, and it was followed in many cases, including, for example, T 121/85 and T 38/86. In deciding if a claim is directed to excluded subject matter or not (does it escape the "as such" clause) before the EPO, a determination is required as to the "technical contribution" made to the known art.

\subsubsection{The Demise of the Contribution Approach}

The contribution approach lasted for some time before being rejected. A fundamental objection to it can be summarised as that if one has to consider a "contribution" when deciding if a claim relates to excluded subject matter, then you are in the realm of comparing the invention to the prior art (a "contribution" must be made to something); in other words, an area that should be reserved for considerations of novelty and inventive step.

A number of cases from approximately 1998 onwards (e.g. IBM ${ }^{33}$, Pension Benefits ${ }^{34}$ ) departed from the contribution approach to varying extents, which have, more or less, brought us to the current position before the EPO. In summary, this position is that any hardware will be enough to overcome the low threshold for patentable subject matter, but that inventive step can only come from the technical features of a claim. If then the claim is essentially, for example, software that when run on a computer controls the computer to do business a new way, although the use of a computer and the internet will get you over the hurdle of patentable subject matter, the fact that there is nothing technically new and inventive means that the claim will fail for lack of inventive step.

Drawing again on the summary of case law provided in Aerotel, Jacob LJ explains how for some time the EPO had been happily applying the contribution approach...

“... But then the EPO took a different course or courses, a course or courses relied upon by both appellants here. A trilogy of cases of particular importance fall for discussion, Pension Benefits (2000), Hitachi/Auction method (2004) ${ }^{35}$ and Microsoft/Data Transfer (2006). ${ }^{36}$ They represent the most important of the latest decisions of the Boards in this field...."

33 T1173/97

$34 \mathrm{~T} 931 / 95$

$35 \mathrm{~T} 258 / 03$

$36 \mathrm{~T} 424 / 03$ 
In Pension Benefits, the Board indicated that the mere presence of technical means in an apparatus claim is enough to remove it from the exclusion from patentability. In Hitachi/Auction Method, this was also extended to cover method claims that refer to some technical means.

In Microsoft Data Transfer, considering the difference between different formulations of computer related claims, the Board indicated that:

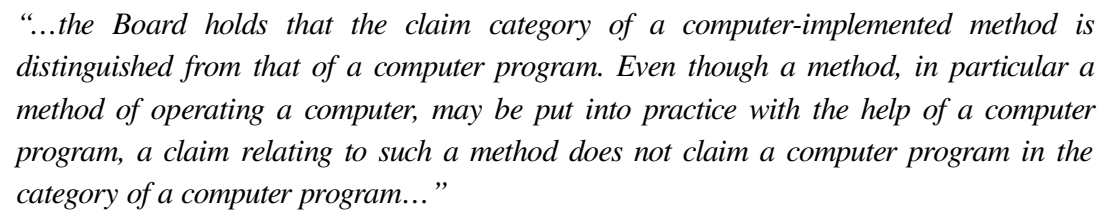

In view of the differences between some of these decisions, a referral was made by the President of the EPO to the Enlarged Board, discussed below. However, before discussing in detail the decision G3/08, the 1997 IBM decision is worthy of mention, since it gave us an important tool used by the EPO today in assessing such cases. In this decision, the determination was made that a computer program is not excluded subject matter if it is capable of providing a "further technical effect", when run on a computer, over and above the normal interaction of the program with the computer.

The Board stated,

"...It is thus necessary to look elsewhere for technical character in the above sense: It
could be found in the further effects deriving from the execution (by the hardware) of the
instructions given by the computer program. Where said further effects have a technical
character or where they cause the software to solve a technical problem, an invention
which brings about such an effect may be considered an invention, which can, in
principle, be the subject-matter of a patent."

The Board went on to indicate that

"The Board takes this opportunity to point out that, for the purpose of determining the extent of the exclusion under Article 52(2) and (3) EPC, the said "further" technical effect may, in its opinion, be known in the prior art. Determining the technical contribution an invention achieves with respect to the prior art is therefore more appropriate for the purpose of examining novelty and inventive step than for deciding on possible exclusion under Article 52(2) and (3)."

The contribution approach, which was introduced so easily in Vicom, was dispatched with similar verbal flourish.

Referring briefly now back to Aerotel, Jacob LJ produced a detailed analysis of the case law and statute and demonstrated how it is clear that there are decisions taken by Boards that are "different" and that in the interests of clarifying these matters, which relate to a highly commercially significant area, the EPO's highest authority, the Enlarged Board, should step in to clear the air.

\section{The EPO Today: Opinion G3/08 of the Enlarged Board of Appeal and Some Current Cases}

There has been historical disagreement between the judges of some member countries (e.g. the UK) and the EPO Boards. As mentioned above, this has been mentioned in various decisions of the respective courts in different countries. Jacob LJ in the Aerotel judgement acknowledges that there is 
no means for a referral to be made to the Enlarged Board via a decision of a court of a member state (no matter how high). However, there is a clear indication that, in the view of the court, the approach followed by the EPO is not correct.

On the other side, in a subsequent EPO decision, Duns Licensing Associates ${ }^{37}$, as well as dealing with the appeal in question, a response was made to Jacob LJ's suggestions in Aerotel. The Board says:

"the "technical effect approach" endorsed by Lord Justice Jacob in the Aerotel/Macrossan judgement (see paragraphs Nos. 26(2) and 38) ...is not consistent with a good-faith interpretation of the European Patent Convention in accordance with Article 31 of the Vienna Convention on the Law of Treaties of $1969 .^{38,}$

It appears that the Board was responding to the suggestion of Jacob LJ in Aerotel that the matter be referred to the Enlarged Board.

This exchange was summarised by Neuberger LJ in Symbian ${ }^{39}$ as follows:

“...This Court in Aerotel (e.g. in [24] and [25]) suggested that it might be adopting a somewhat different approach from that taken by the Board in some of its decisions. Similarly in Duns (e.g. in [12 and 13]) the Board indicated that it was taking a different approach from that adopted by the Court of Appeal. Indeed, each tribunal was rather deprecatory about the approach of the othersee, for instance, [25] of Aerotel (where the approach of the Board in different applications was described as "mutually contradictory") and [12] of Duns (where it was suggested that the approach adopted in Aerotel was "not consistent with a good-faith interpretation of the [EPC]")...."

Eventually, a referral ${ }^{40}$ was made and Opinion G3/08 of the Enlarged Board was issued on 12th May 2010 .

\subsection{The Structure of the EPO}

A few preliminaries about the structure of the EPO will be helpful before going into the specific details of this Opinion. The EPO has a number of sections and divisions that are charged under authority of the EPC itself to execute certain tasks. ${ }^{41}$ These include the receiving section, ${ }^{42}$ the search divisions ${ }^{43}$ and the examining divisions ${ }^{44}$, which are all responsible for the stages in the processing of a European application (as their names would suggest) from filing to grant.

On top of this, a judicial body of the EPO is made up of its Boards ${ }^{45}$, which come in various guises, including both "technical" and "legal". When a decision is made by the receiving section or one of the divisions mentioned above, the applicant normally has the right of appeal to a Board. The

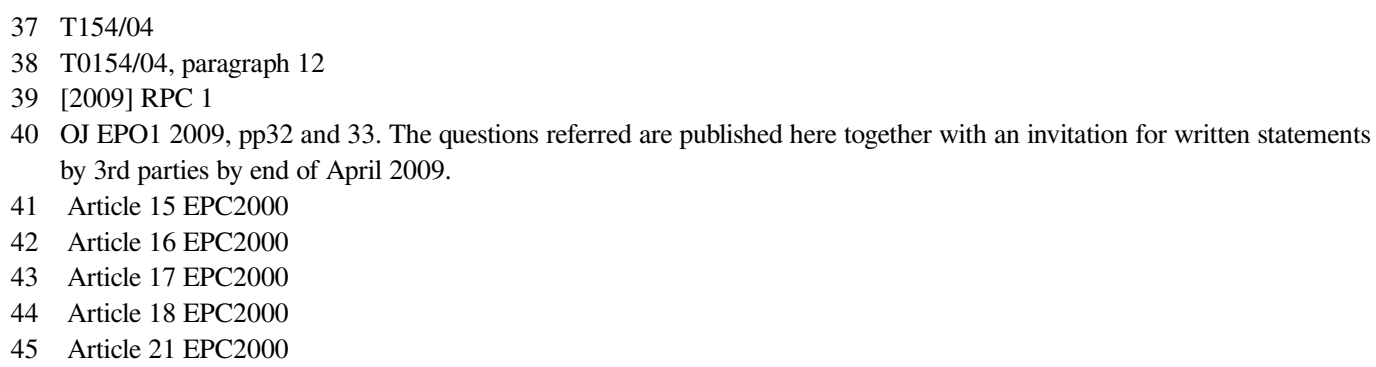


decisions of the Boards are almost always final. In practice and on a day-to-day basis, clients are advised that the final word on a matter before the EPO is as heard before one of the Boards.

There is however higher authority and this is the Enlarged Board. ${ }^{46}$

The function of the Enlarged Board is enshrined in the EPC as follows:

(1) In order to ensure uniform application of the law, or if a point of law of fundamental importance arises:

(a) the Board of Appeal shall, during proceedings on a case and either of its own motion or following a request from a party to the appeal, refer any question to the Enlarged Board of Appeal if it considers that a decision is required for the above purposes. If the Board of Appeal rejects the request, it shall give the reasons in its final decision;

(b) the President of the European Patent Office may refer a point of law to the Enlarged Board of Appeal where two Boards of Appeal have given different decisions on that question.

(2) In the cases referred to in paragraph $\underline{1(a)}$ the parties to the appeal proceedings shall be parties to the proceedings before the Enlarged Board of Appeal.

(3) The decision of the Enlarged Board of Appeal referred to in paragraph 1(a) shall be binding on the Board of Appeal in respect of the appeal in question.

A first point to note is that in the preamble to the article, it is clearly stated that the purpose of the Enlarged Board is not simply to provide another forum for disgruntled patentees or for opponents to have another opportunity to argue the merits of their case because the first Board did not agree with them. Rather, it is policy driven in that its function is the "uniform application of the law".

Indeed, in the document entitled "Basic proposal for the revision of the European Patent Convention", drawn up by the EPO Administrative Council in October 2000, which was to lead to the drafting and bringing into effect of EPC2000, the current version of the EPC, it was stated with reference to Article 11 that

"It is expected that the involvement of national judges in important cases before the Enlarged Board will continue in future to provide valuable input, to help bring about international recognition of these decisions and, in so doing, to further the harmonisation of patent case law in Europe."

Article 11 EPC itself specifically provides that:

"The Administrative Council, after consulting the President of the European Patent Office, may also appoint as members of the Enlarged Board of Appeal legally qualified members of the national courts or quasi-judicial authorities of the Contracting States, who may continue their judicial activities at the national level..." 47

Thus, clearly the EPO's Enlarged Board is a significant legal body concerned with the uniformity of substantive patent law both before the EPO and, through its wider effect and influence, on national

46 Article 112 EPC2000
47 Article 11 EPC2000 
courts too (albeit indirectly).

The Enlarged Board does not provide an additional level of jurisdiction in the classical sense. Rather, it will rule when the case law of the Boards becomes inconsistent or when an important point of law arises.

In keeping with these aims and goals, the ways in which a matter can come before the Enlarged Board are restricted and narrowly interpreted. Typically, it is the Boards themselves and the President of the EPO that can refer a question to the Enlarged Board. In the first case, the Enlarged Board issues a "Decision", ${ }^{48}$ while in the latter case it issues an "Opinion." 49 In addition, in some rare circumstances, a party adversely affected by a decision of a Board can refer a matter to the Enlarged Board. $^{50}$

\subsection{Opinion G3/08}

If ever it could be said of a decision that the reasoning is more significant than the outcome, then this is the defining one. As I will explain below, the end result of the decision was that the Enlarged Board effectively refused to answer the questions put to it. It is not strictly within the remit of the Board actually to refuse to decide a case. What they must do is examine the grounds for admissibility to it and, if these are not found to be satisfied, the decision is deemed inadmissible. The reasoning behind such a refusal is often extremely instructive.

\subsubsection{The Questions}

Before discussing in some detail the Opinion of the Enlarged Board, we must first look at these questions that were referred. These questions (followed by a brief discussion of each and the decisions that gave rise to them) are as follows:

\section{Question 1}

Can a computer program only be excluded as a computer program as such if it is explicitly claimed as a computer program $?^{51}$

The asserted difference was between decisions T1173/97, ${ }^{52}$ making no distinction between categories of claims, especially between computer-implemented claims and computer program claims, and $\mathrm{T} 424 / 03,{ }^{53}$ making a distinction between these two categories.

\section{Question 2}

A) Can a claim in the area of computer programs avoid exclusion under Art. 52(2)(c) and (3) merely by explicitly mentioning the use of a computer or a computer-readable data storage medium?

B) If Question 2(A) is answered in the negative, is a further technical effect necessary to

\footnotetext{
48 Art 22(1)a EPC2000

49 Art 22(1)b EPC2000

50 Art 22(1)c EPC2000. In December 2007 EPC2000 came into effect and with it the availability of "a petition for review" of a decision of a Board may be filed on limited grounds, but this is not strictly relevant to the present discussion.

51 Section 3.1, Referral G3/08

52 Emphasis was placed on the function of the program rather than the manner in which it is claimed.

53 Emphasis was instead placed on the manner in which the computer program is claimed.
} 
avoid exclusion, said effect going beyond those effects inherent in the use of a computer

or data storage medium to respectively execute or store a computer program $?^{54}$

The asserted difference that gave rise to this question was between decisions T1173/97 and T258/03. As explained above, under T1173/97, computer programs are methods, and, in order to have a technical character, they must demonstrate a "further technical effect". In contrast, under T258/03, a method acquires a technical character simply by involving technical means.

\section{Question 3}

A) Must a claimed feature cause a technical effect on a physical entity in the real world in order to contribute to the technical character of the claim?

B) If Question 3(A) is answered in the positive, is it sufficient that the physical entity be an unspecified computer?

C) If Question 3(A) is answered in the negative, can features contribute to the technical character of the claim if the only effects to which they contribute are independent of any particular hardware that may be used $?^{55}$

The asserted difference, was between T125/01 and T424/03 on the one hand and T163/85 and T190/94 on the other. Under the latter, a technical effect on a physical entity in the real world is required so as to avoid the exclusions discussed above, whereas under the former, the technical effects can be confined to the computer programs (and computers in which they run) themselves.

\section{Question 4}

A) Does the activity of programming a computer necessarily involve technical considerations?

B) if Question 4(A) is answered in the positive, do all features resulting from programming thus contribute to the technical character of a claim?

C) if Question 4(A) is answered in the negative, can features resulting from programming contribute to the technical character of a claim only when they contribute to a further technical effect when the program is executed $?^{56}$

The asserted difference was between decisions that related to the act of programming a computer. According to some, a programmer's activity, i.e. writing a computer program, falls within the exclusions of Article 52(2)(c) (T833/91, T204/93, and T769/92) ${ }^{57}$, whereas according to others (T1177/97 and T172/03) $)^{58}$, it does not.

\subsection{2 "Different Decisions"}

As shown, giving rise to each of the questions were a pair (or sets) of decisions identified by the President, which were said to be "different decisions". However, as mentioned above, two decisions, although reaching different conclusions on different legal grounds, are not, in the eyes of the EPO,

\footnotetext{
54 Section 3.2, Referral G3/08

55 Section 3.3, Referral G3/08

56 Section 3.4, Referral G3/08

57 These decisions considered computer programming to be a "mental act" undertaken by a programmer.

58 In contrast to the previous set of decisions, these two decisions both essentially considered the act of programming a computer to be technical or "involve technical considerations".
} 
necessarily "different”. Accordingly, to summarise the Enlarged Board's Opinion, each of Questions 1 to 4 was deemed inadmissible.

The decisions were clearly different in a normal dictionary definition sense of the word; the 18-page letter of referral written by the President of the EPO to the Chairman of the Enlarged Board of Appeal, Mr Peter Messerli, explains this clearly and explicitly. However, the EPO's Enlarged Board is not primarily driven by dictionary definitions of words. Rather, it is driven by the policy and statutory aims laid down for them. In other words, reading between the lines (and based on my own interpretation), if, in the view of the Enlarged Board, the patenting community at large was in any doubt as to how a decision would be made by an Examining Division when considering subject matter of this nature, then it is likely that the Enlarged Board would have come down one way or the other to answer the questions put to it. In the end, it did not, which leads us to conclude that the Enlarged Board didn't consider there were sufficient differences or inconsistencies to warrant an opinion for the "uniform application" of the law.

The Enlarged Board openly acknowledged that there was a difference between some of the decisions mentioned in the referral. For example, the opinion included the following:

"Thus finally the Board had arrived at a conclusion which clearly contradicted the position (or rather one of the positions) taken in T1173/97. T1173/97 declared, "Furthermore, the Board is of the opinion that with regard to the exclusions under Article 52(2) and (3) EPC, it does not make any difference whether a computer program is claimed by itself or as a record on a carrier ... ," (Reasons, point 13), whereas T424/03 stated, "The subject-matter of claim 5 has technical character since it relates to a computer readable medium, i.e. a technical product involving a carrier (see decision T258/03 - Auction method/Hitachi ....)", ,59

Surely, you might think, this must mean that the decisions referred to are "different". Not different enough, it seems.

The Board explained:

"There was a period of approximately seven years between the issuance of the two decisions, a period which, although not very long in legal terms, is nonetheless compatible with the notion of development of the case law. ${ }^{\text {,60 }}$

"Development of the law is an essential aspect of its application, whatever method of interpretation the judge applies, and is therefore inherent in all judicial activity.

Consequently, legal development as such cannot on its own form the basis for a referral, only because case law in new legal territory does not always develop in linear fashion, and earlier approaches may be abandoned or modified.

Otherwise the "different decisions" feature of Article 112(1)(b) EPC would lose its meaning. While the development of the law may superficially appear to give rise to different decisions within the meaning of that provision, on its own it cannot justify a referral to the Enlarged Board. ${ }^{61}$

Next, the vexing question of "what does "technical" actually mean"? Again, no answer from the

59 G3/08, paragraphs 10.7 .1 and 10.7.2

$60 \mathrm{G} 3 / 08,10.9$

$61 \mathrm{G} 3 / 08,7.3 .1$ 
Board. They stated:

\begin{abstract}
"We do not attempt to define the term "technical". Apart from using this term in citing the case law, in what follows the Enlarged Board only makes the assertions that "a computerreadable data storage medium" and a cup have technical character and that designing a bicycle involves technical considerations, in order to be able to explore the consequences of that case law. It is to be hoped that readers will accept these assertions without requiring a definition of exactly what falls within the boundaries of "technical". 62
\end{abstract}

The Board was clearly wary of making a rod for its own back (and for those of applicants and other Boards in the future).

The lack of definition of "technical" from the Enlarged Board may not be prejudicial in practice. Although a clear and concise definition of this term would have been well received by some in the software and patent communities, as it seems to be central to the analysis of these matters, in practice, advisors and practitioners are, largely, able to reach repeatable and reliable conclusions on these matters. ${ }^{63}$ Furthermore, given the nature of the word and the world, it is certainly possible that any acceptable definition arrived at today will seem out of date in ten years' time.

However, it could be argued that this is not a good reason not to define such a crucial term. Much of the reasoning of the Enlarged Board as to why the referral was ultimately inadmissible relates to the fact that case law changes and is not a static entity. Surely then, by this same logic, it could be argued, that the definition of the word "technical" could simply be updated, once/if it became clear that the definition was inadequate. This would not cause two decisions (in which the different definitions appeared) to be "different", but would simply represent a development of the law as an essential aspect of its application.

On a final point, irrespective of my comments that the decision of the Enlarged Board was not particularly surprising, other serious objections have been raised against the reasoning of the Enlarged Board in G3/08. In particular, it has been submitted that in refusing to answer the questions, the Board acted against the provisions of the Vienna Convention. ${ }^{64}$

\title{
3.5 Some Examples of Current EPO Practice
}

This is then the way the law stands at present in Europe, and we can see it in the way examination is conducted by Examining Divisions of the EPO and, by extension, by the way decisions of Boards consider these matters. For an up-to-date exposition of this, I now discuss two recent unexceptional decisions of the EPO Boards.

\subsubsection{T1225/10 Nintendo Co Ltd}

The first decision is, T1225/10 Nintendo Co Ltd, related to EP07106962.9, which was an application for a patent in the area of gaming systems. The invention related to a video game and the control of characters in the game. Characters are controlled to move amongst objects and interact with them, e.g. by striking them.

$62 \mathrm{G} 3 / 08,9.2$

63 As much as on other issues of substantive law.

64 Pila, Justine, Software Patents, Separation of Powers, and Failed Syllogisms: A Cornucopia from the Enlarged Board of Appeal of the European Patent Office (May 1, 2010). Cambridge Law Journal, Forthcoming; Oxford Legal Studies Research Paper No. 48/2010. Available at SSRN: http://ssrn.com/abstract=1612518. 
In fact, in the independent claims there were two technical features that, in the view of the Board, provided novelty. These were: first, the storage of a second data field, in which a character can be located, being made up of objects and being identical to a first field but rotated relative to it; and second, that contact direction determination is based on contact points on the player and not on an object which is struck.

As these solved different and unrelated problems, the inventive step analysis conducted by the Board was a parallel exercise in that two unrelated objective technical problems were identified starting from the closest prior art. The Board found on the facts that one of these inventions (contact direction determination based on contact points on the player ) was inventive, while the other one (storage of a second data field) was not.

Interesting though this is, the main point of relevance here is the discussion regarding excluded subject matter. The Board states in Section 4 entitled "Technical Nature":

\footnotetext{
"Implementation of the previously mentioned game rules - inherently non-technical subject-matter excluded under Article 52(2)(c) EPC - is in the form of a storage medium storing a game program that controls display and game data processing (claim 1) on the one hand, and by corresponding means of the game apparatus (claim 8) on the other. In either case implementation involves technical means so that, following the approach of T931/95 (OJ EPO 2001, 441) and T258/03 (OJ EPO 2004, 575), the claimed storage medium and game apparatus are technical, Article 52(1) EPC."
}

In other words, since the subject of the application uses technical means, it is an "invention" insofar as the requirements of Article 52 are satisfied.

The Board then goes on in Section 6.1 to consider inventive step and says:

\begin{abstract}
"The invention of claims 1 and 8 is "mixed" as it has both non-technical aspects (relating to the game rules) and technical aspects (relating to their implementation). In assessing inventive step of such a "mixed" invention the Board adopts the approach as set out in T1543/06 (Gameaccount), reasons 2, which is based foremost on T641/00 (OJ EPO 2003, 352). Thus, only those features that contribute to technical character are to be taken into account when assessing inventive step."
\end{abstract}

This decision has been issued since G3/08 but did not even refer to it. This may have been due to the timing of the hearing and prosecution of the appeal or because all G3/08 did was to confirm that the position before it was clear enough so that no further substantive comment was needed from it. Only four decisions were referred to by the Board, but these decisions are themselves the product of years of evolution and change and so represent the current EPO consensus on this matter.

The Board then continued further (my emphasis added):

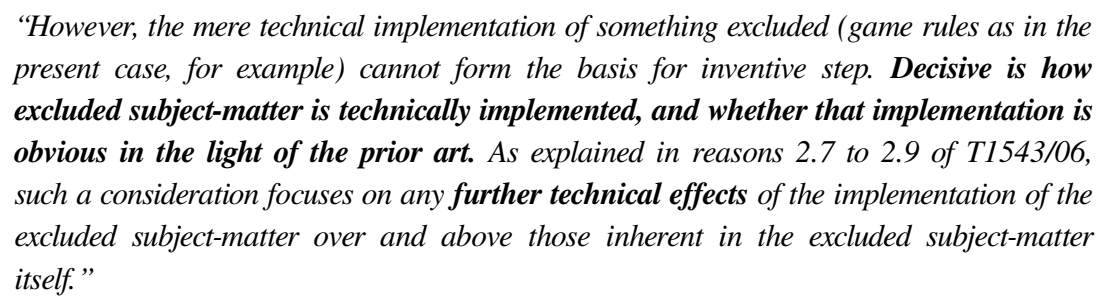

In other words, what they will still look for is a further technical effect, and not be too concerned if 
the implementation of the invention includes excluded subject matter, just so long as some further technical effect is provided.

This recent example is of course but one decision on the subject issued since the Enlarged Board made their pronouncements in G3/08. This decision is by no means a last word on the subject (as no decision of a Board can be), but it does show the way the EPO quite easily and systematically proceeds through these tricky waters. What is more, applicants, when attending this hearing and handling the prosecution of the application, would have had no doubt as to the rationale and approach that the Board would have taken. This, above many other considerations, may be the reason as to why the Enlarged Board felt it unnecessary and not possible under the provisions of the EPC to answer the questions raised under $G 3 / 08$.

\subsubsection{T0174/09 Lucent Technologies Inc.}

The second example I will consider is T0174/09. This decision relates to an application in which the invention related to a telephone, including a speed dial memory and a "a speed dial updating unit", which was arranged to automatically update the speed dial memory based on calling history. A "score keeping unit" was provided to maintain a count of the number of calls to each outgoing telephone number. The nub of the invention was that the speed dial updating unit set a threshold, against which a count maintained by the score keeping unit was compared. The threshold was based on at least one of a measure of time and a number of calls.

This claim was found to lack novelty; so, the applicant's three auxiliary requests were then considered.

As the decision states:

“...Claim 1 of each auxiliary request differs from claim 1 of the main request only by its last feature, which reads as follows: "wherein the threshold is based on both a measure of time and a count of a number of calls" (first auxiliary request), "wherein the threshold is based on a measure of time during which the score keeping unit (113) records a count of a number of calls" (second auxiliary request), and "wherein the threshold is based on the amount of call time for each outgoing telephone number" (third auxiliary request). ..."

The Board dismissed the appeal indicating that the distinguishing feature, i.e. "any criterion as to whether a called telephone number is considered as a candidate for the speed dial memory is of a subjective nature and is therefore a non-technical decision at the free disposal of the skilled person...Thus, claim 1 of each of the auxiliary requests lacks inventive step."

Why something that is of a "subjective nature" need necessarily be "non-technical" is not expanded on (perhaps though because it is done by an individual). However, the EPO's method for dealing with such inventions, whether right or wrong, appears to be clear.

\section{$4 \quad$ Some Thoughts on Bilski}

Having been through the positions in the EPO and UK in some detail now, let us turn to look briefly at Bilski and some parallels or differences that exist between the US system on the one hand and the EPO and UK systems on the other hand, as regards patentable subject matter.

\subsection{No Specific Guidance...}


The Supreme Court's decision in Bilski, has been written about widely, and, as a European attorney, I will not comment in detail on its merits. Whilst it was felt that it was useful in concluding that the "machine or transformation test" is not the exclusive test to be applied, it has been noted that no guidance was given by the Supreme Court as to how to determine patent eligibility when the test is not satisfied. ${ }^{65}$ Indeed, some have viewed it as a missed opportunity to provide clarity from the highest court as to the delineation of the boundaries of patentable subjection. ${ }^{66}$

One cannot help but wonder if in fact the absolute clarity sought is somewhat of a mirage. Even in places like, say, the UK, where these subjects have been explored in great detail and we have a defined test ${ }^{67}$, although helpful, there is still always a judgement call to be made as to how to answer the four questions. On balance, however, having a defined and clear procedure and set of rules as to how a determination will be made must be considered preferable.

\section{2 ...But Some Similarities of Approach}

There are plenty of US-based parties on both sides of the argument as to the merits of business method patents, and the arguments on both sides are well rehearsed. The Bilski decision was controversial by the standards of such an esoteric area of law. Indeed, it even has reached the public at large. The Washington Post commentator Rob Pegoraro commented:

\footnotetext{
"The Supreme Court had an easy call to make in a patent-law case and took the easy way out -- leaving problems with software and business-method patents for another court or Congress to solve.....The case ... involved an infuriating sort of intellectual-property overreach. ${ }^{68}$
}

The decision is interesting as it reflects some differences and also possibly some similarities between aspects of US and European patent law. It has long been a gripe of applicants in Europe that the differences between the practice of different offices do little to promote innovation and technological development and much to line the pockets of lawyers. Clearly the system has ultimately to serve its users. If the relationship between the system and its users the is perceived to break down, in my opinion this would be undesirable.

On a reading of the Bilski decision, I find a degree of common purpose and understanding between the EU and the US as regards the patent processes relating to software whilst, not suggesting they are the same.

First, Kennedy J states: "Section 101 is a "dynamic provision designed to encompass new and unforeseen
inventions", 69

This brings to mind the Enlarged Board's refusal to define "technical". Whilst we might like to know what they think it means, any definition of such a word, and one which could have such effect on the

\footnotetext{
65 Bilski: A "Flipped Vote And Then A Damp Squib”, Richard H. Stern, EIPR Vol 33, Issue 2, 2011, pp115 - 122

66 "Patentable Subject Matter in Bilski v Kappos, 130 S. Ct. 3218 (2010)", Jad Mills, Harvard Journal of Law and Public Policy, January 1st 2011. In pointing out the missed opportunity, the author in fact goes further and criticises the Court arguing that Justice Kennedy “... effectively precluded the Federal Circuit from articulating any categorical rule that would provide true clarity, and instead invited the Federal Circuit to address these issues in a case by case manner".

67 The four point test of Aerotel.

68 Online Washington Post, June 28, 2010.

69 Bilski, Opinion of Kennedy J, Section II.B.2
} 
potential scope of patentable materials, will be difficult if the risk of excluding future, as yet unforeseen, inventions is to be avoided.

He continues, stating that even if a business method fits into the statutory definition of a "process", that does not mean that an application claiming that method should be granted ${ }^{70}$. It must also satisfy the requirements of (inter alia) novelty and non-obviousness.

This resonates with the EPO's view on such matters that just because an application relates to an "invention", does not mean it is patentable, since it must still satisfy the requirements of novelty and inventive step. See, for example, the discussion above in Section 2.4.2 regarding the demise of the Contribution Approach. The EPO of course goes further in requiring the technical effect and technical solution to a technical problem, to the extent that non-technical subject matter is deemed old and incapable of contributing to an inventive step.

Stevens $\mathbf{J}$ continued along a similar vein in some ways. In the introduction ${ }^{71}$ to his judgement, he states

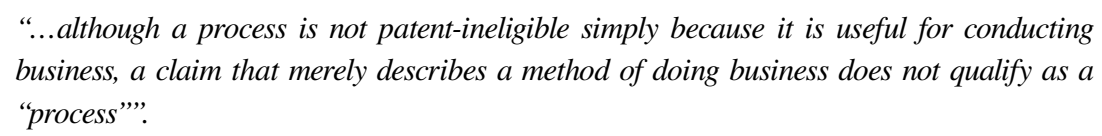

This could almost have been taken out of a decision of an EPO Board. ${ }^{72}$

\title{
4.3 Some Developments since Bilski
}

Furthermore, the Bilski decision seems to have emboldened the lower courts in this area. In the recent decision of CLS Bank International v Alice Corporation Pty. Ltd, the US District Court found four ${ }^{73}$ patents invalid for being directed to unpatentable subject matter. What is more striking is that the court granted summary judgement in full to the plaintiff. The court quoted Rule 56 of the Federal Rules of Civil Procedure that stipulates that summary judgement shall be granted:

"If the movant shows that there is no genuine dispute as to any material fact and the movant is entitled to judgement as a matter of law," ${ }^{4}$

Drawn out litigation helps nobody in the long run, generating costs and delay, but it seems quite remarkable to conclude in a case like this that there is no genuine dispute as to any material fact. Continuing, the court discusses what constitutes an "abstract idea" and whether or not it was a good idea to try and produce a definition of one. The court stated:

\begin{abstract}
"there is no clear definition of what constitutes an abstract idea; instead, courts analogize from the standards etched out by the cases just discussed. As the Federal Circuit recently acknowledged, "the Supreme Court did not presume to provide a rigid formula or definition for abstractness" Research Corp. techs. V. Microsoft Corp., 627 F 3d 859, 868 (Fed. Cir 2010) (citing Bilski II, 130 S. Ct. at 3228) ${ }^{, 75}$
\end{abstract}

70 Bilski, Opinion of Kennedy J, Section II.C.2

71 Bilski, Opinion of Stevens J

72 See for example, Koch and Sterzel/X-ray method for optimum exposure (1987) T 26/86

73 US-A-5,970,479, US-A-6,912,510, US-A-7149720 and US-A-7,725,375 all directed to what the patentee described as "an innovative trading platform" which entailed a "computerised system for establishment, settlement, and administration of financial instruments...", CLS Bank International v Alice Corporation Pty. Ltd, pp 2., 9th March 2011

74 CLS Bank International v Alice Corporation Pty. Ltd, Section II.A, quoting Fed. R. Civ. P. 56(a), pp 11

75 CLS Bank International v Alice Corporation Pty. Ltd, Section II.B, pp 17 
Note, as a further example, the similarity here with the view of the Enlarged Board as to the merit in producing a rigid definition of "technical". The terms "technical" and "abstract" approach the problem from different perspectives. In the US, the applicant or patentee is looking to fall outside the definition (of "abstract"), whereas in the UK and Europe the opposite is true: the applicant or patentee is looking to fall inside the definition (of "technical"). However, it appears to me that the USPTO and the US courts are struggling with issues that we have been struggling with in Europe for many years. Whilst not having the statutory mentions of "technical solution"76 and the like, the issues are nevertheless close.

Determining exactly what sort of subject matter people should be able to obtain patents for is difficult. Computer software and business methods are clearly not squarely in the area that legislators would originally have had in mind when considering suitability for patent protection. Hence, they can cause problems on both sides of the Atlantic (and the English Channel). Indeed, it has even been suggested that given the "specific features and requirements" of computer software, it must be queried as to whether or not the creation of a "unique or sui generis" right might even be appropriate. ${ }^{77}$ I think, in general though, the system we have in Europe and the UK works, despite the differences discussed above. It would, however, of course be preferable to have a greater degree of uniformity.

\section{Conclusions}

In conclusion, although tests and the provisions in the EPO and UK may be unpopular with some, one of the important aspects of any patent system, not just for potential software-related inventions, is to provide certainty for third parties and for users of the system. This desire for certainty features in diverse areas of patent law, since the patentee is being given something valuable by the government. On both sides of the central debate regarding the nature of legal protection available for software, certainty is surely preferable to the alternative. I have described here now the way these matters are considered is different as between the EPO and UK: before the EPO the question will almost always come down to a matter of an inventive step and determination as to whether there is an inventive step taking into account the features that contribute to technical character. In the UK, the determination is still based on the original Vicom decision, as modified and applied over the years by the UK courts.

However, the disagreement between the UK and the EPO should not be allowed to obscure the fact that, on a practical level, there is in fact a degree of consensus about - ultimately - what is and is not patentable, even if the way the two offices get there is very different.

Although there is clearly a conflict (in fact, direct contradictory positions) between various Technical Board of Appeal decisions on which the President's referral was based, it remains that practitioners before the EPO representing applicants from all over the world know the principles that will be applied, the tests and factors that will be considered and the manner in which decisions will be taken by Examining Divisions and/or Boards. I believe that the chances of success, on the grounds of patentable subject matter, as between the UK and the EPO, would be very similar, even if under the EPC you will fail for lack of an inventive step, whereas in the UK, you will fail for unpatentable

76 EPC2000, Rule 43(1), “... The claims shall define the matter for which protection is sought in terms of the technical features of the invention..."

77 Protecting Computer-related Inventions in Europe: The Need for Domestic and International legal Harmony, Carole Deschamps, EIPR Vol 33, Issue 2, 2011, pp103-114 
subject matter.

\begin{abstract}
About the Author
Avi Freeman is a partner in Beck Greener, a UK-based firm of European and UK patent and trademark attorneys and litigators. The author has a background in physics and specialises in dealing with patents and patent applications in the area of computer-implemented inventions (hardware and software) before both the UKIPO and the EPO.
\end{abstract}

\title{
Licence and Attribution
}

This paper was published in the International Free and Open Source Software Law Review, Volume 3, Issue 1 (September 2011). It originally appeared online at http://www.ifosslr.org.

This article should be cited as follows:

Freeman, Avi (2011) 'Patentable Subject Matter: the View From Europe', International Free and Open Source Software Law Review, 3(1), pp 59 - 80

\section{DOI: $\underline{10.5033 / \text { ifosslr.v3i1.58 }}$}

Copyright (C) 2011 Avi Freeman.

This article is licensed under a Creative Commons UK (England and Wales) 2.0 licence, no derivative works, attribution, CC-BY-ND.

As a special exception, the author expressly permits faithful translations of the entire document into any language, provided that the resulting translation (which may include an attribution to the translator) is shared alike. This paragraph is part of the paper, and must be included when copying or translating the paper.

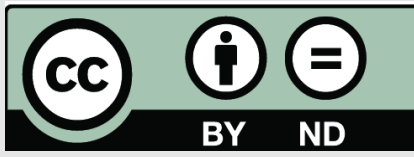

